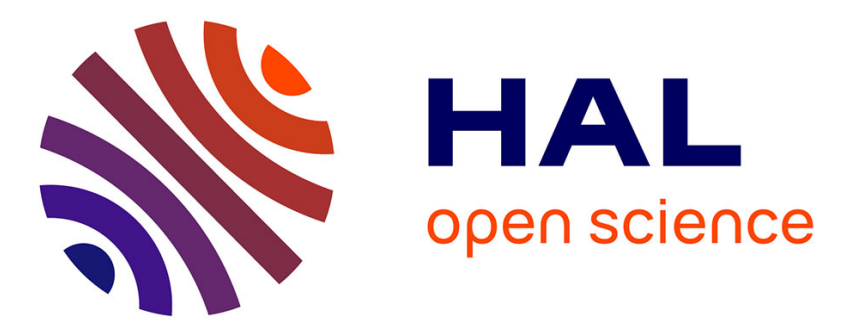

\title{
Transforming Low Socioeconomic Status Schools to Learning for Well-Being Schools
}

\author{
Heilyn Camacho
}

\section{To cite this version:}

Heilyn Camacho. Transforming Low Socioeconomic Status Schools to Learning for Well-Being Schools. 6th IFIP World Information Technology Forum (WITFOR), Sep 2016, San José, Costa Rica. pp.60-67, 10.1007/978-3-319-44447-5_7 . hal-01429757

\section{HAL Id: hal-01429757 https://hal.inria.fr/hal-01429757}

Submitted on 9 Jan 2017

HAL is a multi-disciplinary open access archive for the deposit and dissemination of scientific research documents, whether they are published or not. The documents may come from teaching and research institutions in France or abroad, or from public or private research centers.
L'archive ouverte pluridisciplinaire $\mathbf{H A L}$, est destinée au dépôt et à la diffusion de documents scientifiques de niveau recherche, publiés ou non, émanant des établissements d'enseignement et de recherche français ou étrangers, des laboratoires publics ou privés. 


\title{
Transforming Low Socioeconomic Status Schools to Learning for Well-being Schools
}

\author{
Heilyn Camacho \\ Aalborg University, Aalborg, Denmark \\ hcamacho@hum.aau.dk
}

\begin{abstract}
This article presents the initial finding about the complexity of dealing with a transformation of a low socioeconomic school into a learning for well-being school. The article looks at the problem through the lens of complexity theory to discuss the different components, subsystems and the different kind of changes that need to take place for the transformation process. The article concludes with some suggestions for developing a framework that may help practitioners and researchers when approaching this kind of complex change.
\end{abstract}

Keywords: ICT and education, complexity theory, low socioeconomic status schools, school change, learning for well-being.

\section{$1 \quad$ Introduction}

Over the past 30 years, research community has developed a body of theoretical and empirical work regarding the influence of socioeconomic status (SES) in the students performance. It has showed that: a) students from low socioeconomic families have lower academic achievements, b) Low SES (LSES) environments affects students' growth and cognitive development, c) LSES students have lower innate ability, less favourable attitudes towards school (often they lack of motivation to learn), less ambitious to further education and higher education (they see themselves remaining in the same situation and they do not have role models to follow) and d) poverty negatively affects a student's physical and emotional health, which influences educational outcomes [1] [2][3].

In the other hand, we have The Incheon Declaration 2015 [4], which encourages all countries to provide inclusive, equitable, quality education and life-long learning opportunities for all. It is a transformative vision for education for the next 15 years. Other visions similar to Incheon Declaration are the 21 st century skills program, UNESCO's four pillars for education and Learning for well-being framework. Yet far too many children and youth, especially those from poor and minority families, are relegated to lower quality education and lower quality futures.

Learning for well-being is defined learning "as broad and unconfined to the narrow borders of school-based education; its goals are equally broad, encompassing the physical, spiritual and emotional, as well as the cognitive." [5, p. 55] According with the framework of Learning for well being, "learning is social endeavour, it has important emotional and spiritual components, it is related to cultural context as well as 
individual ways of learning and it occurs not only in our brain but in every part of our body" [5, p. 58]. This definition is aligned with UNESCO's four pillars of education: learning to know, learning to do, learning to live together and learning to be.

Having this view of learning and vision of inclusion, we may ask, is it at possible to achieve learning for well-being in LSES schools? The CREO (believe and create in Spanish) project is an action research project aims to improve the education and life opportunities of students from LSES high schools. This research project deals with the questions about how LSES high schools can be transformed in learning for well-being high schools?

Through the cycle of planning, action, reflection and planning again, we aim to try out different initiatives to change the current situation of one high school in Costa Rica, with the end goal not only of improving the learning and life conditions for those students, but also to develop a framework to facilitate change in LSES high schools, that could be useful for other LSES schools in Costa Rica and outside of the country.

The scope of CREO project is very broad but in this article we focus on the analysis of the complexity to initiate an organizational change at one high school with the aim to implement new teaching approaches and the use of information and communication technologies (ICT) to move the school closer to a learning for well-being school.

The research question for this paper is what systemic approach in terms of multiple changes at different levels could potentially help researchers and practitioners to effectively handle the complex process of transforming a low socioeconomic school?

As this is a research in progress, in this paper we analysis the complexity of the phenomena and provide description of the first actions taken and the first inputs for the possible approach. For the analysis we use complex theory as lens to understand the phenomenon and discuss the challenging situation that a practitioner faces when trying to decide how to start the change process.

\section{Complexity Theory}

Schools have been identified as a complex adaptive systems and researches demand different approaches for schools reforms [6], [7]. For the discussion of the concept of complexity theory we draw extensively on [7], mainly because the limit space in this paper and his focus on school reform. Complexity theory conceptualizes the workings of non-linear systems composed of multiple interacting and diverse elements that influence each other. They are seen as systems that change constantly based on information feedback into the system. This systemic view seems compelling, because nothing stands alone; everything is interconnected and interdependent. Complex systems cannot be understood by analysing the individual components, it should be analysed as a whole, in the case of the schools, it is necessary to understand the relationships among students, teachers, families, communities and administrators to see what emerges from their collective interaction [7].

According to [7], complexity theory offers a holistic framework for understanding the systemic nature of education reform and who proposes the 
Short paper

following questions when designing, implementing and assessing school reforms: "Are initial conditions promising? Will people do things differently and in ways that align with a school's core values? Is power distributed appropriately? Do people have a say? Do students, teachers, parents, and administrators share core values? Are similar rituals, routines, and practices aligned with these values and enacted at multiple levels of the system? Are there logical reasons why the pieces would work in concert and be mutually supportive?" [7, p. 1794]. He identifies two implications of using complexity theory to understand school reforms: a) Look at school reforms as evolving solutions, where the research should analysis the interaction at multiple levels of the system and avoid micromanage fragments of the system and b) Educational reform policies should target at multiple levels of a system and work to effect them simultaneously.

\section{$3 \quad$ Methodology}

The methodology chosen for this project is action research. This is a huge field with different approaches based on participative and pragmatic values. We have decided to use Lewin's [8] nature of action research.

We understand Lewin's main work as explained in [9], where he presents Lewin's planned change approach composed by field theory, group dynamic, action research and three step change model. The fact that we approach the problem as a planned change, does not mean that we understand the research situation as static or linear, all the contrary, we are quite aware of the complexity and changeable elements of this research project, which is the way also as we understand Lewin's approach of working with real world problems.

Field theory focuses on constructing and understanding the situation as a whole, it establish the relationship between the life spaces (holistic view of the individuals and their situation) and the forces and elements that composes it [10]. Another very relevant aspect of the field theory related with this research project is the aspect of theory based method for analysis the real world problem. As [10, p. 490] have stated "Lewin's basic argument was that, if one does not understand the current situation, the forces that are maintaining the current quasi- stationary equilibrium, one cannot even begin to bring about change. Beyond that, field theory allows individuals and groups to explore, understand and learn about themselves and how they perceive the world and how those around them perceive it". Related with group dynamic helps us to understand the behaviour of the different groups involved in the project.

The basic process of action research involves repeated cycles of action and critical reflection upon the action. The implementation of these steps provides a clearer understanding of the situation. Interpreting the information from the first product cycles helps us to make decisions on how to conduct the following cycles and also produces new knowledge. According to [11], Lewin's original model of action research includes 1) analysis, 2) fact-finding, 3) conceptualization, 4) planning, 5) implementation of action, 6) evaluation.

We report data from a high school in the south of Costa Rica, which serves some of 
the most vulnerable (disadvantage) students in the age between 15 and 19, with a modality of three days of teaching per week, from 6:00 pm to 10:00 pm, only the 5 basic subjects. By vulnerable students we mean students that are premature transitioned to adulthood either because they are, or about to become, parents or they have home situation that does not allow them to attend school in the formal systems (for example, they should work to support their homes) or students that have failed in the formal educational system and try to get one more opportunity in this modality. Those students come, usually, from the lower social economic level. To date, the school has a high dropout rate and very low score on state exams.

The high school was created with the aim to be supported by ICT in order to allow flexibility regarding schedule and also different pedagogical approaches that would appeal to the target group. However, so far, the Costa Rican Ministry of Education has not managed to incorporate technology in the modality and the high school is running almost as a normal high school in Costa Rica, but with less resource and less teaching hours for the students.

So far, in the first cycle, we have had collected the following data (from April December 2015): a) Six interviews with teachers (they are around 11). These interviews were focused to know the organizational culture of the school, perception of the teachers about the students and competences and use of ICT, b) Interview with the school leader. The aim of this interview was to know the structure and process of the school and the relationship with the Ministry of Education, parents and community, c) A questionnaire for students to get to know their access and use of technology, d) Three workshops with the teachers. These workshop focused in understanding the challenges of the school and appropriation of the project and problems (first workshop), reporting back the result of the data collection and planning of future actions (second and third workshop), e) One workshop with a group of 15 students. This workshop aimed to hear the students about the school problems, understand their background, motivations and challenges as students and f) Ten interviews with parents. The focus was to get to know students home background, parents economical and educational status, parents perception and interaction with the school.

\section{Data Analysis}

Following the action research methodology, we analysed the data in order to conceptualize the problem and define an overall plan and the first actions to take. We looked at each dataset collected and drew the main issues/aspects of each one. This categorization and interpretation process was guided by the pre-defined aims of the data collection.

In the following paragraphs we present a summary of the fact-finding from the field and fact-finding from the literature (we present very brief description because space limitation), which were used to move to the conceptualization phase of action research. After that, we present the actions defined to approach the problem (planning phase). 
Short paper

\subsection{Fact-finding from the field}

In general, from the data we can say that: a) there is a lacked room for creativity and exploration and very low use of technology in the classroom, this provokes that teaching become one way passive process, where the students listen what the teachers say and take notes or follow the copies of some text book, therefore, students feel bored in the classes; b) according with the teachers, their main challenges are to develop students desire to learn and to have a better future and deal with State regulation that limit their autonomy; c) in the same line leadership main complain is the so many proceeds to follow and documentation to report back to the Ministry of Education; d) for most of the students it is easy to state their goal for their future but their action are counter-productive to achieve the goal (not attending school, not doing homework, etc.); e) students would like a more active high school (participation in the community activities, science exhibition, independence day fest, art festival, graduations, etc.) and a more enjoyable classroom; f) there is not a culture of knowledge creation and sharing neither collaborative learning among the staff of the school, furthermore, there is a lack of common values and shared vision; g) there is not resistance to change from the teachers neither from the leader, they are quite willing to participate in a change process, however, the time often shows up as a constraint to be more active and proactive in the process; $h$ ) there is not interaction among the schools and the families (parents are not involved in the education of their children) not between the school and the community. Actually, the school has a bad reputation within the community. The school is seen as a kind of "last option" school. It is possible to conclude that the community sees the school as one of the worse schools in the town; and j) finally, we identified a lack of competences regarding management and teachers low competences on active learning and use of ICT for teaching.

\subsection{Fact-finding from the literature}

Following Lewin's approach about using theoretical frameworks to analyse the real world situation. The literature recommend LSES schools should be approached differently (small groups, active learning, play based learning, improving teaching quality and leadership competences, among others)[1]-[3]. In the same line, we have the factor of ICT usage for education, which is not only a tool for teaching but a basic skill nowadays.

[12] recommend that for drop out prevention, it is crucial to have a high quality instruction, a school that promotes a positive behaviour and environment. The staff should have the competences and the resources to design learning environments according with the reality of the students, school culture that promotes collaborative learning and connexions with the families.

School culture is fundamental for any reform. Organizational culture is a key factor for organizations and schools are not excluded. [13] has identified six traits that could influence organisational culture in schools (shared vision, traditions, collaboration, innovation, communication and share decision making). Any effort to 
reform schools should involve the field of organizational culture [14]. [7, p. 1791] has stated regarding organizational culture and school reforms "Schools are complex systems. If those in schools don't share common values, the system will not work as well as it might otherwise."

The other field from the theory is the organizational change, which involves the organizational culture [15], the capacity of an organization to share and create knowledge [16] and the capacity to become a learning organization [17].

Four more aspects to consider are: a) the relevance of students centered approach to develop critical thinking, problems solving, reflective skills [18], b) The fundamental role of the leadership in the schools and also in the change process [19], c) the benefit of ICT in management activities [20], and d) multiple strategies interventions for schools and the lack of experimental research addressing schools problems with a multiple levels and components approach [21].

With these two datasets we identified many misalignments between the current practice and how things should be, according with the theory. At this point, we could bring back the [7] questions to understand the systemic nature of the school (theory section). The main question is which node should we approach and how, as the schools does not have the capability to deal with many changes at the same time. We could see that a new pedagogical approach (problem or play based learning) would not be supported by the current organizational culture and organizational structure. The same would happen with the introduction of ICT (for teaching and/or management), as the staff does not have the competences to benefit from it. To run an organizational change - cultural change for example - the current leadership lacks of the necessary competences because his educational background.

We identify mainly three subsystems in the overall system and that each system should be approached with different theories: classroom system (pedagogy theory field), school system (organizational theory field) and community (human development theoretical field). Those three systems interact and influence each other. For the conceptualization phase, we see community as a context of the school (national and local), furthermore, we include into the system a new component technology. The overall understanding is that technology may support and facilitate the transformational process and therefore technology would become one of the components, which would influence and be influenced by the other components. See figure 1.

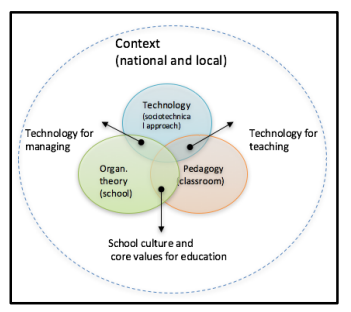

Fig. 1. Conceptualization of the overall system to plan actions

In the planning phase, we have defined three key actions to start the process of 
moving close to a learning for well-being school. These three actions are going to be implemented at the same time responding to the complexity theory:

- Develop leadership competences. One of the strongest nodes in the system is the head of the school. He has influence in the many of the nodes and it is also where the three spheres converge. It is fundamental to develop leader skills to create a share vision, manage change, establish new share values and foster the IT usage - in classroom as well as for managing the school.

- Change the organizational culture of the school, by creating a collaborative and learning organization, furthermore by introducing new common values about students centered methodologies and IT usage and the principles of learning for well-being (the holistic approach of development). Following the complexity theory, it is expected that impacting this node, will have effect on the other aspects of the systems. This action is going to be implemented by creating an online community among the teachers, the leader and the researcher.

- Influence motivation of students by keeping the focus on the end goal. The project is in the process to develop an App which will allow students to establish a long term goal for finishing their high school and set up short term goals to see the progress. Teachers will have access to the App with the idea that they could encourage students to keep on. Later on, it is expected to have some kind of "virtual mentors" in the App, with the aim that former students, from the high school, who has graduated and continue with their higher education, give motivational messages. This action aims to approach the emotional and personal aspects of the students by providing a tool to keep focus on their overall goal. At the moment, March 2016, we are in the planning phase of the online community and the App.

\section{Conclusion}

The complexity of the transformation LSES demands different the theoretical framework to understand and approach the situation. To answer the research question of this paper, we present some preliminary recommendations for a systematic approach to transform LSES schools: a) approach the phenomena with the complexity theory (do not see the problem as parts but a whole) and identify the key nodes to define which are the most relevant nodes to approach first, b) identify the current organizational culture and organizational practice, c) create partnership with external actors to overcome the challenges of knowing multiple theoretical approaches, d) approach the transformation process as an organizational change, as a new practice- pedagogical and organizational - should be established, e) develop leading change competences for the principal, f) to make the process sustainable, create an organizational culture of knowledge sharing and creation, g) define a suitable training program for professional development, according with the inputs from the study of the current situation. 


\section{References}

1. Bøg, M., Dietrichson, J., Filges, T. \& Jørgensen, A.-M. Protocol for 'academic interventions for children and students with low socioeconomic status: a systematic review'. 45 (Det Nationale Forkningscenter for Velgærd, 2014).

2. Curtis, D., Drummond, A., Halsey, J. \& Lawson, M. Peer-Mentoring of Students in Rural and Low-Socioeconomic Status Schools: Increasing Aspirations for Higher Education. 35 (National Vocational Education and Training Research Program, 2012).

3. World Education Forum. Incheon Declaration. (2015).

4. Ilona, K. Learning for Well-being: A Policy Priority for Children and Youth in Europe. A process for change. (Universal Education Foundantion, 2012).

5. Johansson, E. Ecological systems and complexity theory: Toward an alternative model of accountability in education. Complicity Int. J. Complex. Educ. 5, 1-10 (2008).

6. McQuillan, P. J. Understanding small school reform through the lens of complexity theory: It"s 'good to think with.' Teach. Coll. Rec. 110, 1772-1801

7. Lewin, K. in Resolving Social Conflicts / Field Theory in Social Science (American Psychological Association, 2008).

8. Burnes, B. Kurt Lewin and the Planned Approach to Change: A Re-appraisal. J. Manag. Stud. 41, 977-1002 (2004).

9. Burnes, B. \& Cooke, B. Kurt L ewin's Field Theory: A Review and Re-evaluation. Int. J. Manag. Rev. 15, 408-425 (2013).

10. Baskerville, R. \& Wood-Harper, T. A critical perspective on action research as a method for information systems research. J. Inf. Technol. 11, 235-246 (1996).

11. Alaimo, K., Olson, C. M., Frongillo, E. A. \& Briefel, R. R. Food insufficiency, family income, and health in US preschool and school-aged children. Am. J. Public Health 91, 781 (2001).

12. Mac Iver, M. A. \& Mac Iver, D. J. How Do We Ensure that Everyone Graduates? An Integrated Prevention and Tiered Intervention Model for Schools and Districts. New Dir. Youth Dev. 25-35 (2010). doi:10.1002/yd.360

13. 13. Goldring, L. The power of school culture. Leadership November/December, 32-35 (2002).

14. Reigeluth, C. . Chaos theory and the sciences of complexity: Foundations for trans- forming education. in (2004).

15. Schein, E. H. Organizational culture and leadership, fourth edition. (San Francisco, Calif. : Jossey-Bass, 2010).

16. Nonaka, I. The knowledge-creating company : how Japanese companies create the dynamics of innovation. (Oxford University Press, 1995).

17. Senge, P. The Fifth Discipline. 1, (1997).

18. Kolmos, A. et al. Problem Based Learning. (2007). Available at: http://www.unifi.it/tree/dl/oc/b5.pdf.

19. Bartoletti, J. \& Connelly, G. Leadership Matters: What the research says about the importance of principal leadership. 16 (National Association of Elementary School Principals, 2013).

20. Levy, M. \& Powell, P. Information Systems Strategy for Small and Medium Sized Enterprises: an organisational perspective. Strateg. Inf. Syst. 9, 63-84 (2000).

21. Freeman, J. \& Simonsen, B. Examining the Impact of Policy and Practice Interventions on High School Dropout and School Completion Rates: A Systematic Review of the Literature. Rev. Educ. Res. 85, 205-248 (2015).

22. 
Short paper 